\title{
Ultrastructural justification for the transfer of Pleistophora anguillarum Hoshina, 1959 to the genus Heterosporis Schubert, 1969
}

\author{
J. Lom ${ }^{1, *}$, I. Dyková ${ }^{1}$, C. H. Wang ${ }^{2}$, C. F. Lo ${ }^{2}$, G. H. Kou ${ }^{2}$ \\ ${ }^{1}$ Institute of Parasitology, Academy of Sciences of the Czech Republic, Branišovská 31, 37005 České Budějovice, Czech Republic \\ ${ }^{2}$ Department of Zoology, College of Science, National Taiwan University, 1, Sec. 4, Roosevelt Rd, Taipei 107, Taiwan, ROC
}

\begin{abstract}
This study presents the ultrastructure of the microsporidian infecting the trunk musculature of Anguilla japonica and originally described as Pleistophora anguillarum Hoshina, 1959. All stages develop within a special structure, the sporophorocyst (SPC), which is equipped with a thick dense wall. This wall grows along with the growth of the parasites within it. Meronts are uni- to binucleate, which divide and steadily give rise to sporonts. During transition to sporonts the cell coat of the meronts increases its thickness, temporarily featuring thick irregular projections. Eventually a uniformly thick sporont wall is formed, then the sporont cells detach themselves from the wall (= future wall of the sporophorous vesicle, SPV) and start a series of divisions to produce sporoblasts. The SPV wall is compact, has no pores and consists of 2 layers. The presence of the SPC justifies the transfer of the species into the genus Heterosporis. Spores from disrupted SPCs are ingested by macrophages and within them are spread into various body tissues including the outermost layers of the epidermis. From here, they can easily be released to the outside and can contaminate the environment while the host is still alive.
\end{abstract}

KEY WORDS: Microsporidia $\cdot$ Ultrastructure $\cdot$ Heterosporis anguillarum $\cdot$ Pleistophora $\cdot$ Anguilla japonica

Resale or republication not permitted without written consent of the publisher

\section{INTRODUCTION}

Microsporidia which infect sarcocytes of the trunk musculature of fish are represented by the genera Pleistophora Gurley, 1893, Kabatana Lom, Dyková \& Tonguthai, 2000 and Heterosporis Schubert, 1969. The type species of the latter, $H$. finki Schubert, 1969 originally described from connective tissue of Pterophyllum scalare from a pet shop in Germany (Schubert 1969a,b), was later found to produce massive infection of the myocytes of the same host (Michel et al. 1989). Another muscle-infecting species, Heterosporis schuberti Lom, Dyková, Körting \& Klinger 1989, was described from ornamental fish Ancistrus cirrhosus and Pseudocrenilabrus multicolor. Later, an unnamed spe-

*E-mail: lom@paru.cas.cz cies, Heterosporis sp. of Lom, Dyková \& Tonguthai, 1993 was recorded from Betta splendens. The key feature of the genus Heterosporis is the presence of a sporophorocyst, which is a dense, rather solid wall enclosing all developmental stages of the parasite, i.e., meronts, sporonts and sporophorous vesicles with sporoblasts and spores. Comparing our own findings on Heterosporis with data in the literature, we came to the conclusion that Pleistophora anguillarum Hoshina, 1959 is a species of the genus Heterosporis. In view of the economic importance of this species, several papers have dealt with this species, e.g., Hashimoto et al. (1976, 1979), Hashimoto \& Takinami (1976), Kano \& Fukui (1982) and Kano et al. (1982). The paper by T'sui \& Wang (1988) showed 5 electron micrographs of this species, but the authors still treated it as a Pleistophora species. 
Since an overall description of this species can be found in T'sui et al. (1988), we have concentrated in this paper on ultrastructural features confirming beyond doubt its assignment to the genus Heterosporis. The species deserves attention since it has the pathogenic potential to endanger Southeast Asian eel cultures and it presents a possible threat to eel cultures everywhere. A parallel can be seen in the example of the nematode Anguillicola crassus introduced to Europe.

\section{MATERIAL AND METHODS}

Material for this study was obtained from experimental infections and the following steps were taken:

Purification of spores for experimental infection. Eels showing the 'curved body', physical symptoms of 'beko disease', were immobilized by ice and the infected muscle was removed and digested in $0.05 \%$ trypsin in phosphate buffer solution (PBS) at $\mathrm{pH} 8.0$ for 3 to $4 \mathrm{~h}$ with constant stirring. The digests were then filtered through 5 layers of gauze, and the filtrate was centrifuged at $800 \times g$ for $10 \mathrm{~min}$. The precipitate was discarded and the supernatant was centrifuged again at $3000 \times g$ for $30 \mathrm{~min}$. The precipitate was resuspended in PBS to a final spore concentration of $10^{9} \mathrm{ml}^{-1}$. Spore purification was done by Percoll gradient centrifugation as described in T'sui et al. (1988). For experimental infection, the spore concentration was adjusted to $10^{7} \mathrm{ml}^{-1}$.

Experimental infection. The elvers ( $0.15 \mathrm{~g}$ each) were immersed in $100 \mathrm{ml}$ of spore suspension solution $\left(10^{7} \mathrm{ml}^{-1}\right)$ at $25^{\circ} \mathrm{C}$ for $12 \mathrm{~h}$ and then cultured in aquaria in the laboratory and fed with Tubifex sp. for 20 to $23 \mathrm{~d}$. Most of the infected elvers showed the obvious 'curved body' physical symptoms of 'beko disease'.

Electron microscopy. The elvers were sacrificed and the infected tissues were fixed in $2.5 \%$ glutaraldehyde in $0.1 \mathrm{M}$ phosphate buffer, $\mathrm{pH} 7.2$, at $4^{\circ} \mathrm{C}$ for $3 \mathrm{~h}$ and then postfixed in $1 \%$ osmium tetroxide in the same buffer at $4^{\circ} \mathrm{C}$ for $2 \mathrm{~h}$. After dehydration in an alcohol gradient series, the infected tissues were embedded in Spurr's epon. The ultrathin sections were cut on a Reichert OMU3 ultramicrotome and stained with uranyl acetate and lead citrate. Electron micrographs were made with a Hitachi H7100 and with Jeol JEM 1010 electron microscopes operated at 100 and $80 \mathrm{kV}$, respectively.

\section{RESULTS}

The parasite stages develop within a special structure, the sporophorocyst (SPC), which is bounded by a dense envelope, 230 to $500 \mathrm{~nm}$ thick. The SPC wall grows along with the growth and division of the parasites within it. It eventually forms a cyst up to about $200 \mu \mathrm{m}$ in diameter, although some SPCs stop growing quite early and may not exceed $20 \mu \mathrm{m}$ in diameter and contain only a few mature spores. The SPC only ruptures at a late stage of infection when macrophages may ingest separate spores.

The SPC wall contains a variety of developmental stages (Fig. 1). Meronts, uni- or binucleate cells, are squeezed between the walls of the SPC and sporophorous vesicle (SPV) (Figs. 2 \& 3). Their plasmalemma is overlain with a thin lamina of dense substance, raised into irregular projections. There are only a few meronts in the SPC, but these divide to produce additional meronts and steadily give rise to new sporonts.

During the transition of uni- or binucleate meronts to sporonts, the dense substance at the surface of the meronts gradually increases in volume (Fig. 4) and the newly accrued substance forms conspicuous, thick, irregular projections (Fig. 5). Later, the tops of the projections flatten and the plasmalemma bears a coat of uniformly thick, amorphous matter, the actual SPV wall. The next step is detachment of the sporont plasmalemma from the SPV wall (Fig. 6). The space thus formed is filled with a fine granular substance. The sporont which has stacks of endoplasmic reticulum in the cytoplasm, its nuclei having divided (Fig. 8), segments into separate sporoblasts (Figs. 7 \& 9). The SPV wall may undergo further differentiation (Fig. 10); beneath an amorphous dense lamella 30 to $40 \mathrm{~nm}$ thick there is a layer of less dense material 90 to $210 \mathrm{~nm}$ thick, delimited towards the outer lamella by a rippled boundary.

The dense wall of the sporophorocyst has rather fuzzy surfaces and on the outer side it is contiguous with the layer of disintegrated sarcoplasm. The muscle fibres may run parallel to the SPC wall (Fig. 11), or their microfibrils are positioned perpendicularly to it and almost touch it with their frayed ends (Fig. 12).

The immature spore contains 2 large dense globules (about 1.5 to $2 \mu \mathrm{m}$ in size) in the space of the future posterior vacuole (Fig. 13); these globules are considered to be identical with the secretion granules associated with the Golgi which are also found in other microsporidian spores. Mature spores have a huge posterior vacuole filled with dense floccular material and encircled by turns of the coiled polar tube. There are 33 to 46 (mean 40, $\mathrm{n}=30$ ) turns (in what can be termed macrospores) arranged in a single layer at midspore length and in 3 irregular superimposed layers in the posterior half of the spore (Fig. 15). The anchoring disc of the polar tube is situated terminally and has a typical appearance, with 7 alternating dense and lucent layers at the bottom above the thick shaft of the 


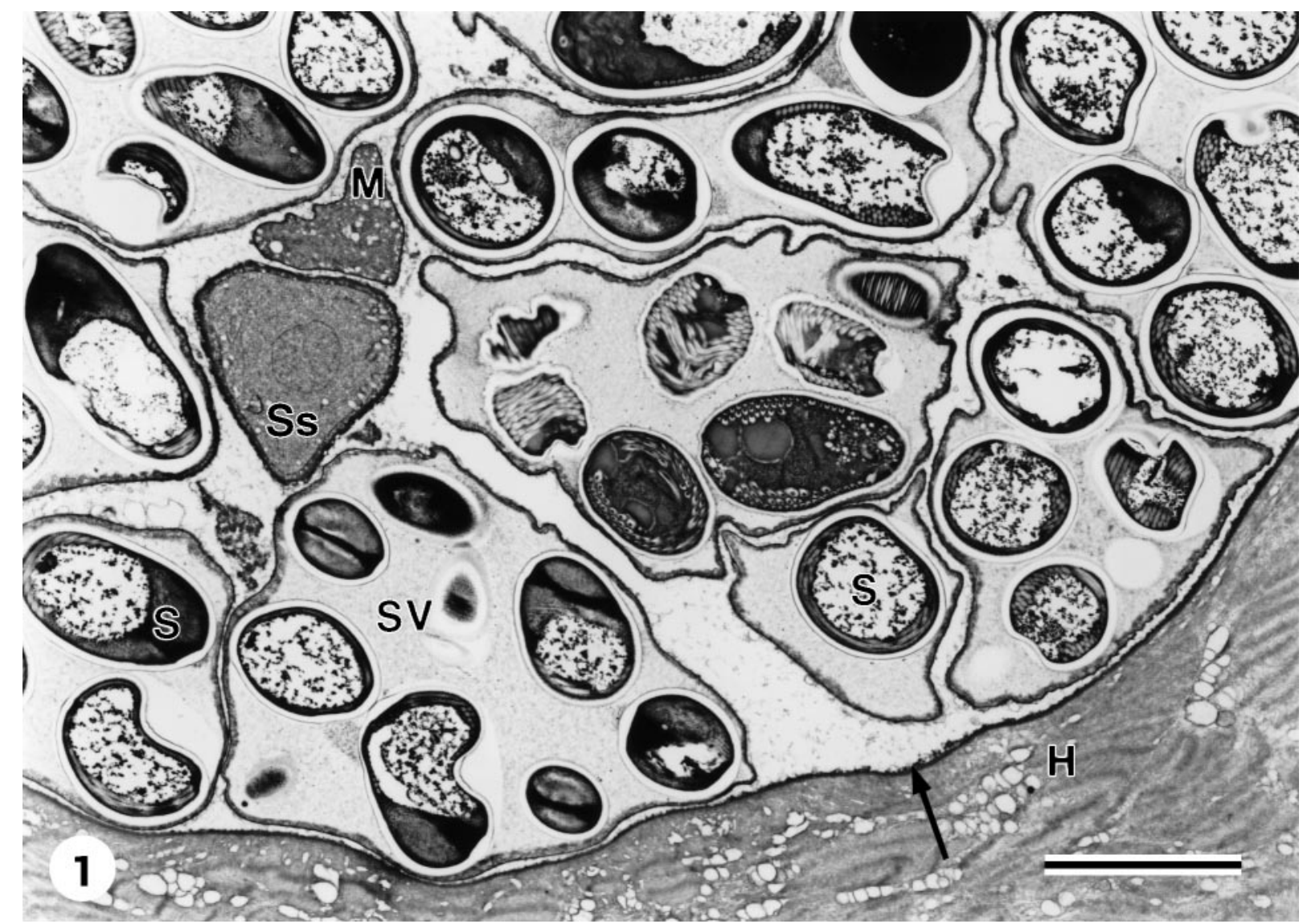

Fig. 1. Overall view of a part of a sporophorocyst of Heterosporis anguillarum; its wall (arrow) is in contact with trunk muscle (H) of its host, Anguilla japonica. Sporophorous vesicles (SV) with mature spores (S), sporont (Ss) and meront (M) can be seen. Scale bar $=5 \mu \mathrm{m}$

tube. The substance of the disc forms a cylinder which extends downward for some distance in between the lucent walls of the proximal end of the tube (Fig. 14). Flat polaroplast lamellae, consisting of 2 layers, are densely spaced around the proximal straight end of the tube. Posteriorly, the lamellae are looser and undulated. In the cytoplasm between the posterior vacuole and the polaroplast a single nucleus and a few polyribosomal strand lie sidewise. The endospore averages $180 \mathrm{~nm}$ in thickness at mid-body length and about $70 \mathrm{~nm}$ at the apex (Fig. 15).

The possibility of autoinfection must be considered since occasionally one can encounter extruded polar tubes discharged into the neighbouring muscle fibres (Fig. 17)

In the heavily invaded muscle tissue the SPCs are eventually disrupted and macrophages ingest the released spores and are virtually full of them. They migrate into various body tissues including the skin, which they pervade, extending up to the outermost layers of epidermis (Fig. 16). There they can easily break open and the spores are thus released into the environment while the host is still alive.

\section{DISCUSSION}

Following incomplete observations on spores of Pleistophora anguillarum, as the parasite was called at that time, by Hashimoto \& Takinami (1976), a more thorough study of the parasite was undertaken by T'sui \& Wang (1988). Using a light microscope, they were able to describe early stages which they called uninucleate schizonts and uninucleate sporonts. The early stages produced an external cyst wall and underwent sporogony. Sporonts gave rise to multinucleate plasmodium and these structures were observed to some extent with the electron microscope (T'sui \& Wang 1988). Inside the cyst, they observed sporophorous vesicles ('pansporoblasts' in their terminology) in different stages of development. No details on the developing sporonts and ultrastructure of the cyst 


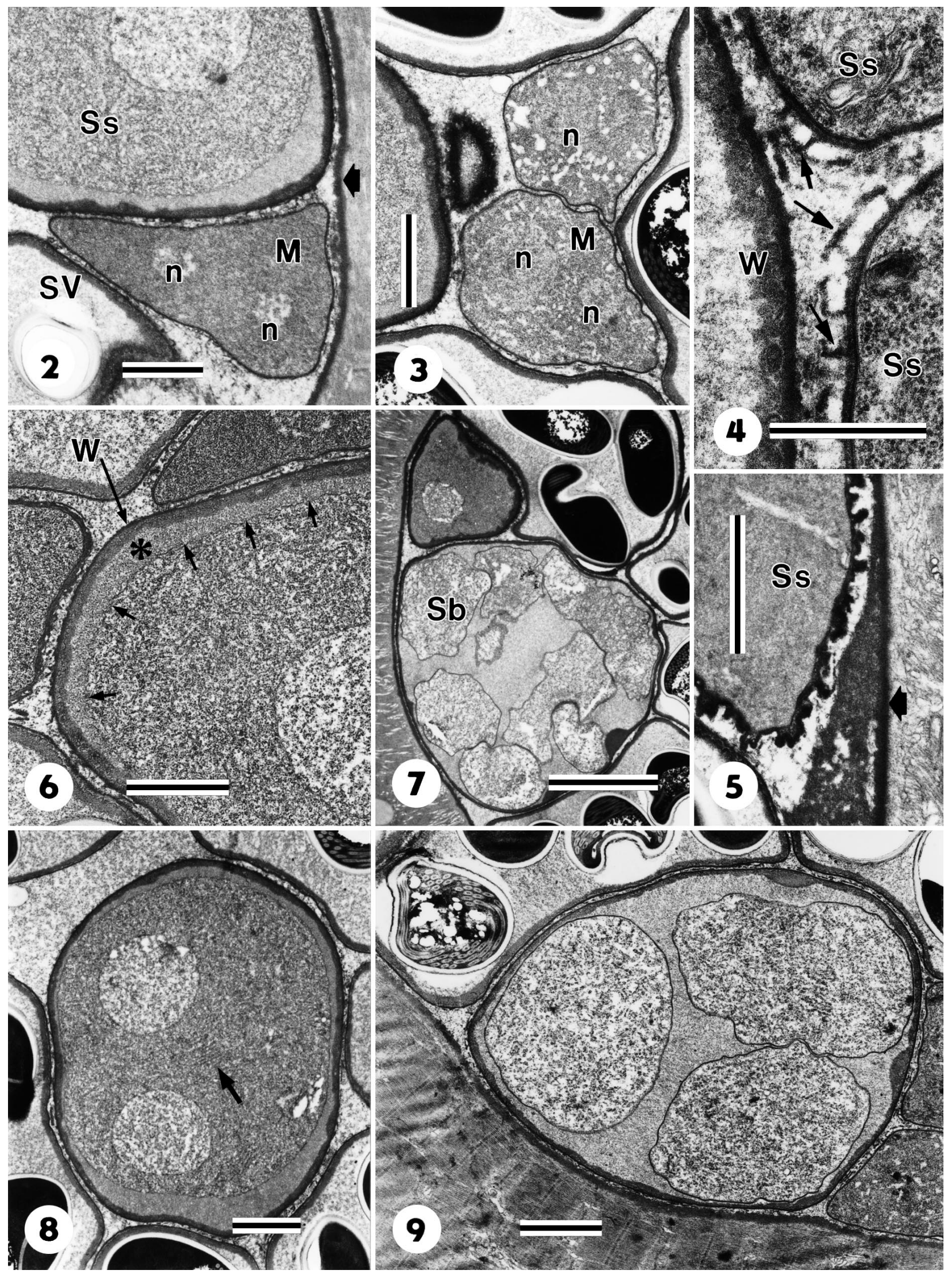


Figs. 2 to 9. Heterosporis anguillarum. Figs. 2 \& 3. Meronts of $H$. anguillarum (M) with 1 or 2 nuclei (n) wedged between sporophorous vesicles (SV), sporonts (Ss) and sporophorocyst wall (arrowhead). Fig. 4. The dense substance (arrows) on the plasmalemma of nascent sporonts (Ss). W: wall of the sporophorous vesicle. Fig. 5. Projections of dense substance on the surface of the sporont-to-be (Ss); arrowhead: sporophorocyst wall. Fig. 6. Plasmalemma (small arrows) of the sporont detached (asterisk) from the sporophorous vesicle wall (W). Fig. 7. A young sporophorous vesicle with developing sporoblasts (Sb). Fig. 8. A binucleate sporont with a stack of endoplasmic reticulum (arrow). Fig. 9. Sporophorous vesicle with 3 cells destined to divide further into sporoblasts. Scale bars $=2 \mu \mathrm{m}$, except in Fig. 4 (scale bar $=0.5 \mu \mathrm{m})$ and Fig. 7 (scale bar $=5 \mu \mathrm{m})$

wall were supplied. The authors had no doubts that the parasite's proper place was within the genus Pleistophora.

When describing Heterosporis schuberti, Lom et al. (1989) suggested that in view of similarities between the life cycle of Pleistophora anguillarum as described by Hoshina (1951) and stages of H. schuberti, P. anguillarum should be transferred into the latter genus as H. anguillarum (Hoshina, 1951). The present observations confirmed that the organisation of the sporophorocyst and its contents-merogony and sporogony stages - are in agreement with observations on H. schuberti. In the eel material, perhaps because of advanced infection, we failed to find the initial meronts, which would have initiated the SPC wall. On the other hand, the present material, its fixation being far superior to the formalin-fixed $H$. schuberti specimens studied by Lom et al. (1989), yielded a much better picture of the structure of the advanced stages and of the SPC and SPV walls. Without a doubt, the SPC cannot be compared to a xenoma, as was done by Michel et al. (1989), who wrote '...light and electron microscopy permitted recognition of subspherical cysts (within muscular fibers) as xenomas...' (p. 106). Xenomas are completely different structures in that they represent the entire transformed host cell, in the cytoplasm of which the parasites stages are embedded, which functions as an entity surrounded by a xenoma wall. Michel et al. (1989) also described the presence of diplokarya in the merogony stages on the evidence of a single, not very convincing micrograph. We did not see any diplokarya in the present material, nor were they seen by Hoshina (1951), T'sui \& Wang (1988) in $H$. anguillarum or by Lom et al. (1989) in H. schuberti.

The morphology of Heterosporis anguillarum differs quite clearly, as does that of the other species of the genus, from the genus Pleistophora, as exemplified by the species P. typicalis (Canning et al. 1979, Canning \& Nicholas 1980) or P. hyphessobryconis (Lom \& Corliss 1967). Two significant differences are the presence of the SPC and absence of little canals leading through the massive SPV wall. Canning \& Hazard (1982) showed that the then existing genus Pleistophora was an assemblage of at least 3 genera. It is also clear that the former 'pleistophoras' parasitizing fishes should be further split into at least 3 genera: Pleistophora, Heterosporis and another genus for the 'pleistophoras' infecting gonads such as Pleistophora mirandellae (M. Pekkarinnen \& J.L. unpubl. obs.).

Lom et al. (1989) came to the conclusion that the SPC wall around the small early meronts of Heterosporis schuberti was of parasite origin and the fact that the later stages were completely identical with those observed in the present study constitutes the evidence that the same origin of the SPC wall may be presumed in $H$. anguillarum. The actual genesis of the wall in the earliest stages of infection will be the topic of the next study.

Hung et al. (1998) compared sequence data of SSU rRNA of Heterosporis anguillarum with those of several other microsporidia and found that the sequences were most similar to Vavraia oncoperae and cautioned that the low mean distance values between the sequences of $V$. oncoperae and Trachipleistophora hominis should be satisfactorily explained before $H$. anguillarum can be ultimately assigned to the genus Heterosporis. To explain the proximity of $V$. oncoperae and $T$. hominis, Cheney et al. (2000) offer the possibility that both species may perhaps be congeneric: a Vavraia species from a haematophagous insect feeding on man may be able to initiate a human Trachipleistophora infection. Cheney et al. (2000) also report that the Pleistophora typicalis clade is only distantly related to Heterosporis ('Pleistophora') typicalis, the sequence divergence being $>11.5 \%$. Nilsen (2000) also tested microsporidian affinities using the SSU rRNA sequence data of a number of genera and species. He found that with the exception of Nucleospora, all fish microsporidia occurred in the same group and concluded that Heterosporis anguillarum does not belong to the genus Pleistophora. Nilsen's (2000) results support the earlier proposed transfer (Lom et al. 1989) into the genus Heterosporis. It is a sister taxon to $P$. mirandellae (probably also not a true Pleistophora), and they are both separate from the clade comprising $P$. typicalis and related pleistophoras. Hence, both morphological and molecular evidence coincide and support the assignment of the former Pleistophora anguillarum into the genus Heterosporis. 


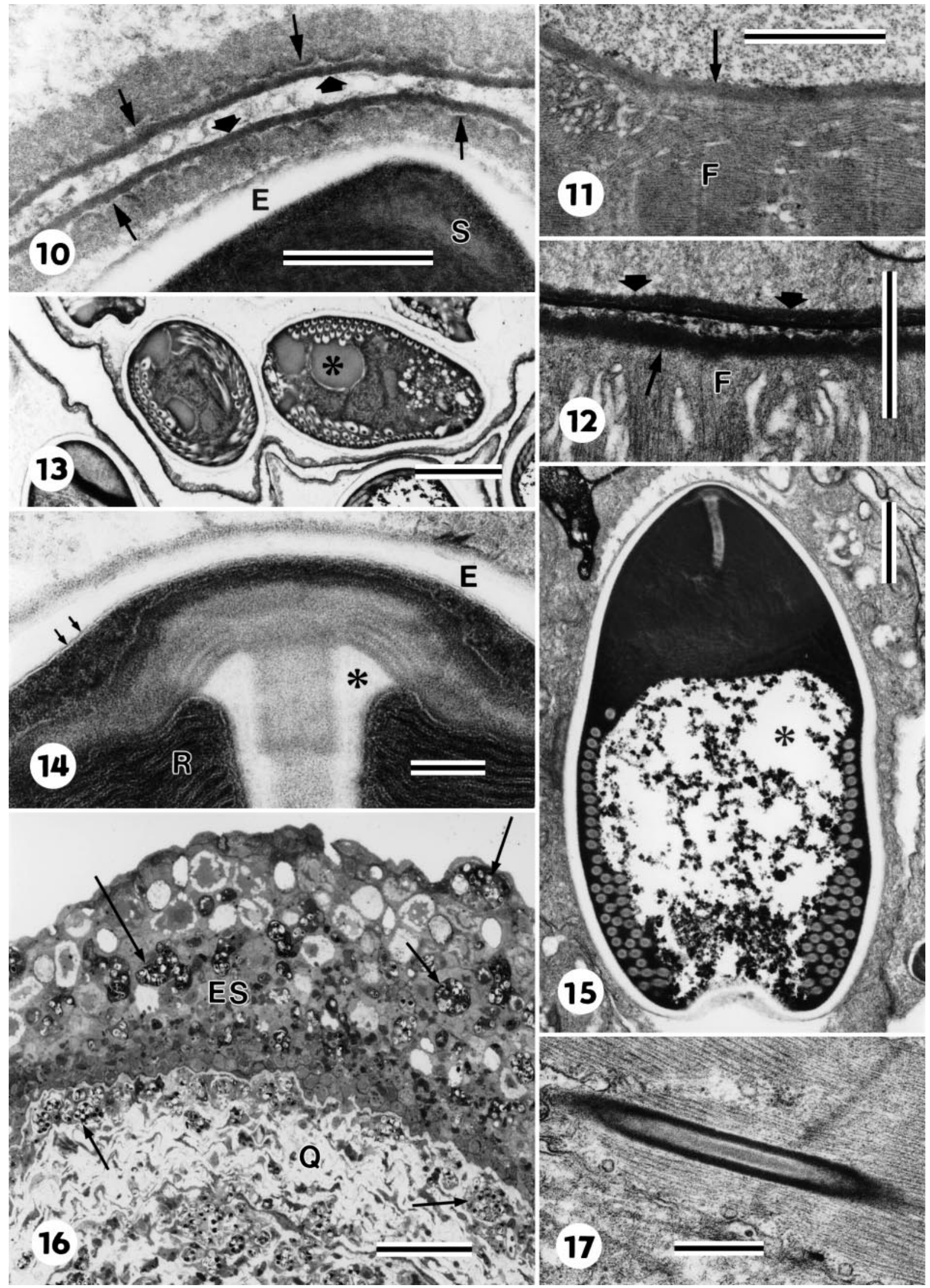


Figs 10 to 17. Heterosporis anguillarum. Fig. 10. Two apposed sporophorous vesicle walls each with a rippled boundary (arrows) beneath the outer dense lamella (arrowheads). E: endospore of the adhering spore (S). Scale bar $=0.5 \mu \mathrm{m}$. Fig. 11 . Sporophorocyst wall (arrow) adhering to parallel muscle fibrils (F). Scale bar $=2 \mu \mathrm{m}$. Fig. 12. Sporophorocyst wall (arrow) with muscle fibrils (F) attached perpendicularly. Arrowheads: wall of sporophorous vesicle. Scale bar $=1 \mu \mathrm{m}$. Fig. 13. Dense globules (asterisk) inside an immature spore. Scale bar $=2 \mu \mathrm{m}$. Fig. 14. Anchoring disc at the spore apex; asterisk: lucent layer of the shaft of the polar tube. R: polaroplast, E: endospore, arrows point at exospore. Scale bar $=0.1 \mu \mathrm{m}$. Fig. 15. Longitudinal section through a mature spore; asterisk: posterior vacuole. Scale bar $=1 \mu \mathrm{m}$. Fig. 16. Macrophages packed full with spores (arrows) on their way to and through the epidermis (ES) surface. Q: corium. Scale bar $=50 \mu \mathrm{m}$. Fig. 17. Extruded polar tube extending through the muscle fibre. Scale bar $=0 . \overline{5 m}$

Acknowledgement. This paper was supported by the Grant Agency of the Czech Republic, Grant No. 524/98/0589.

\section{LITERATURE CITED}

Canning EU, Hazard EI (1982) Genus Pleistophora Gurley, 1893: an assemblage of at least three genera. J Protozool 29:39-49

Canning EU, Nicholas JP (1980) Genus Pleistophora (Phylum Microspora): redescription of the type species, Pleistophora typicalis Gurley, 1893 and ultrastructural characterisation of the genus. J Fish Dis 3:317-338

Canning EU, Hazard EI, Nicholas JP (1979) Light and electron microscopy of Pleistophora sp. from skeletal muscle of Blennius pholis. Protistologica 15:317-332

Cheney SA, Lafranchi-Tristem NJ, Canning EU (2000) Phylogenetic relationships of Pleistophora-like microsporidia based on small ribosomal; DNA sequences and implications for the source of Trachipleistophora hominis infections. J Eukaryot Microbiol 47:280-287

Hashimoto K, Takinami K (1976) Electron microscopic observations of the spores of Plistophora anguillarum, a microsporidian parasite of the eel. Bull Jpn Soc Sci Fish 42:411-419 (in Japanese)

Hashimoto K, Sasaki Y, Takinami K (1976) Conditions for the extrusion of the polar filament of the spore of Plistophora anguillarum, a microsporidian parasite of Anguilla japonica. Bull Jpn Soc Sci Fish 42:837-845 (in Japanese)

Hashimoto K, Sasaki Y, Takinami K (1979) Inhibitory effect of amines on polar filament extrusion by Plistophora anguillarum spore. Curr Microbiol 3:137-140

Hoshina T (1951) On a new microsporidian, Plistophora anguillarum n.sp., from the muscle of the eel, Anguilla japonica. J Tokyo Univ Fish 38:35-49

Hung HW, Lo CF, Tseng CC, Peng SE, Chou CM, Kou GH (1998) The small subunit ribosomal RNA gene sequence of Pleistophora anguillarum and the use of PCR primers for

Editorial responsibility: Wolfgang Körting,

Hannover, Germany diagnostic detection of the parasite. J Eukaryot Microbiol 45:556-560

Kano T, Fukui H (1982) Studies on Pleistophora infection in eel, Anguilla japonica. I. Experimental induction of microsporidiosis and fumagillin efficacy. Fish Pathol 16:193-200 (in Japanese)

Kano T, Okauchi T, Fukui H (1982) Studies on Pleistophora infection in eel Anguilla japonica. II. Preliminary test for application of fumagillin. Fish Pathol 17:107-114 (in Japanese)

Lom J, Corliss JOC (1967) Ultrastructural observations on the development of the microsporidian protozoon Plistophora hyphessobryconis Schäperclaus. J Protozool 14: $141-152$

Lom J, Dyková I, Körting WH, Klinger H (1989) Heterosporis schuberti n.sp. a new microsporidian parasite of aquarium fish. Eur J Protistol 25:129-135

Michel C, Maurand J, Loubès C, Chilmonczyk S, de Kinkelin P (1989) Heterosporis finki, a microsporidian parasite of the angel fish Pterophylum scalare: pathology and ultrastructure. Dis Aquat Org 7:103-109

Nilsen F (2000) Small subunit ribosomal DNA phylogeny of microsporidia with particular reference to genera that infect fish. J Parasitol 86:128-133

Schubert G (1969a) Ultracytologische Untersuchung an der Spore der Mikrosporidienart, Heterosporis finki gen. n., sp. n. Z Parasitenkd 32:59-79

Schubert G (1969b) Elektronenmikroskopische Untersuchungen zur Sporonten- und Sporenentwicklung der Mikrosporidienart Heterosporis finki. Z Parasitenkd 32:80-92

T'sui WH, Wang CH (1988) On the Pleistophora infection in eel. I. Histopathology, ultrastructure and development of Plistophora anguillarum in eel, Anguilla japonica. Bull Inst Zool Acad Sin (Taipei) 27:159-166

T'sui WH, Wang CH, Lo CF (1988) On the Pleistophora infection in eel. II. The development of Pleistophora anguillarum in experimentally infected elvers, Anguilla japonica. Bull Inst Zool Acad Sin (Taipei) 27:249-258

Submitted: July 4, 2000; Accepted: September 27, 2000

Proofs received from author(s): December 7, 2000 